\title{
Dinner at Dinosaurland: Invention, Dialogue, \& Solidarity in the Early Childhood Classroom
}

\author{
Selena L. Hoy, Jessica L. Lea, and Erin E. Flynn
}

Selena L. Hoy is a bicultural, bilingual social worker. She is outreach coordinator for TELL, a mental health and suicide prevention nonprofit organization in Tokyo, Japan. She received her MSW from Portland State University in 2017 and has particular interest and experience working with underserved children, refugees, and immigrants.

Jessica Lea is a licensed clinical social worker at an intensive outpatient program in Portland, Oregon. She received her MSW from Portland State University in 2017 and has worked and volunteered in multiple sectors supporting underserved members of the community.

Erin Elizabeth Flynn is an associate professor in the Child, Youth, and Family Studies program at Portland State University. She is an educational researcher who specializes in language and literacy development during the early years, with an emphasis on the social, emotional, and linguistic power of storytelling. Email: flynn2@pdx.edu

This Ideas from Practice piece highlights a storytelling practice called story circles as a routine classroom practice with the potential to catalyze shared ideas in the classroom by spurring invention, dialogue, and invention. Examining the slow-growing unfolding of stories about the invented world of Dinosaurland, we illuminate the potential of the language of story as a way for children to sustain and develop ideas through sharing imagined worlds.
The child is made of one hundred ... a hundred worlds to discover a hundred worlds to invent a hundred worlds to dream.... Loris Malaguzzi (1998)

In hopes to give "witness to memories, gestures, and ways of thinking from a world of childhood too often overlooked or forgotten" (Gandini \& Morrow, 2016, p. xv), we share the joy and invention that occurred in the context of a routine classroom storytelling activity called a story circle. In the story circles, children told stories about the invented world of Dinosaurland, introducing, sustaining, and evolving an idea over time. The idea of Dinosaurland as an invented world quickly worked its way into the common culture of the children in the classroom, catalyzing new lines of storytelling. A catalytic event is an experience which sparks deep interest in children, motivating their pursuit of learning in a particular direction (Wiggins \& McTighe, 2005). The introduction of Dinosaurland into the children's stories along with the subsequent dinner at Dinosaurland stories served as a catalytic event for this group of children as the Dinosaurland adventures assumed a place of prominence in the story circle and in the children's indoor and outdoor classroom play.

Pedagogically, the intent of story circles is to create space for children to author the ideas that motivate and make up classroom life. We will show how one group of children used this newfound classroom space to build an invented world together, and in the process, exchange and sustain ideas in ways not often attributed to young children.

\section{Setting the context}

The joyful invention of Dinosaurland occurred in the context of an urban Head Start classroom in the U.S. Pacif- 
ic Northwest. The classroom offered play-based preschool curriculum, complemented by teaching practices like engaging children in immersive study of child-driven ideas. In this half-day preschool program serving children aged 3-5, a linguistically and ethnically diverse group of children, many from refugee and immigrant backgrounds, learned together, developing shared ideas and interests.

This article stems from a research partnership between the urban Head Start classroom and a local university. Interested in enhancing teachers' existing repertoire of child-centered learning practices, a collaborative team consisting of a teacher educator and two master's of social work students worked with the team of classroom teachers, Loretta, Sofia, and Madison (all names are pseudonyms). The teachers engaged children in a weekly storytelling activity, story circles, as a catalyst for learning and the development of classroom community life.

Story circles are a small-group storytelling activity in which children take turns telling their own story each week. Story circles have been used in educational, therapeutic, and community-building settings, and have long been valued for centering the common cause of participants in a dialogic exchange (Flynn, 2016; Flynn et al., 2019). Children in this classroom participated in story circles over the course of the school year, introducing and developing ideas and ways of telling stories. In the process, they built a distinct classroom culture populated by characters, places, and processes of their own invention.

In a story circle, a small group of four to six children sit in a circle on the carpet accompanied by a classroom teacher. The teachers designate a classroom prop as a talking stick to signal whose turn it is to tell a story. Each child takes a turn telling a story of their own choosing. The teachers' primary role is to listen and facilitate turn taking. They refrain from attempting to extend children's stories or asking questions of children, trusting instead that children's stories will get longer, more detailed, and more complex by being told and retold within the circle (Flynn, 2020). Instead, teachers provide primarily positive or neutral comments, intervening in the storytelling as little as possible so that children can more freely nominate and sustain ideas in the circle.

\title{
Introducing and sustaining the idea of Dinosaurland
}

The Dinosaurland stories began simply enough with the children's shared interest in dinosaurs and Alex's (one of the preschool students) introduction of Dinosaurland as a place to play in one's stories. Reflecting on the genesis of the idea and the flurry of thinking it inspired in the children, in the following vignettes we trace the development of Dinosaurland and show how Alex's catalytic story "Dinner at Dinosaurland" moved children's storytelling in new directions.

The story circle group included Alex, Damon, Emma, Nadim, Sadiq, Miguel, and Aaden, children of recent immigrants from the Middle East and North Africa and those from European American, African American, and Latino families.

Alex introduced the idea of Dinosaurland in February.

\author{
Once upon a time. I went to Dinosaurland. \\ Then. I played with dinosaurs. \\ I went in volcano.
}

Then I went to mommy and told all about it.

The end.

Over the course of the next four months, children told over 20 stories about Dinosaurland, returning to the invented world week after week. The origin and importance of the idea for this group of children was not immediately clear. "Was this a real place?" the teachers in the room wondered. Maybe in our city? They had never heard of it. One of the researchers, Jessica, had a child the same age as the children in the classroom. Did she know of this place? No, she did not. A map search turned up nothing. Well, the children had been studying dinosaurs in class. 
Perhaps they had read a book about it? From this uncertain origin, we continued to wonder and listen, captivated by the strong sense of reality Dinosaurland held for the children, even as its status as a place felt more ambiguous for us as adults.

Dinosaurs were an excellent medium for the children's imaginations. Within the first few stories where Dinosaurland was introduced, the children also referenced places everyone was familiar with, like school, the park, or home. Eventually Dinosaurland became a place where one could visit at will, dropping in after breakfast and returning home in time for lunch.

$$
\begin{aligned}
& \text { Then I went on the bus. } \\
& \text { Then after that. } \\
& \text { I go to Dinosaurland. } \\
& \text { And I saw dinosaurs. } \\
& \text { I went on a ride. } \\
& \text { Then after that. } \\
& \text { I went back home. } \\
& \text { Aaden }
\end{aligned}
$$

Though Dinosaurland began with Alex, the idea did not belong to any one child. It was a shared idea, open to all and visited frequently. For some, it was a ferocious landscape with volcanoes, while for others, it was a theme park.

$$
\begin{aligned}
& \text { Once upon a time I was walking to Dinosaurland. } \\
& \text { Again. And l'd been. } \\
& \text { And then I went to Disneyland. } \\
& \text { So that's the end. } \\
& \text { That's the end. } \\
& \text { Damon }
\end{aligned}
$$

Eventually Dinosaurland became a plot device that allowed the children to integrate themselves and, indeed, each other in their stories. Family members had cameos in these stories, and then classmates began to appear, sometimes taking on central roles.

$$
\begin{gathered}
\text { I went to Dinosaurland. } \\
\text { Played with dinosaurs. } \\
\text { Hmm. Miguel and Damon came too. } \\
\text { We played with dinosaurs. } \\
\text { Alex }
\end{gathered}
$$

As the weeks progressed, children began to include more and more of their peers as characters in the stories they told. This proved popular, and we could see children's eyes brighten when they were mentioned in a friend's story.

Then we went to the park. Me and Alex.

Then we went to Dinosaurland. Me and Alex.

Fight a flying dinosaur. 
Then we went on a flying dinosaur.

Then we went back home ...

Then I went to Damon's house again.

And Alex's house.

Nadim's house.

And Miguel's house.

And Sadiq's house.

Then we all went to Dinosaurland.

Then we all go to the dinosaur. Again.

Then the dinosaurs taked us everywhere.

Then we all have fun together. Over there.

Then we all love toys.

Then we all went back home.

Aaden

Dinosaurs played an important part of this imaginary landscape, and children had a remarkably good grasp of their names and traits. They would recite lists of multisyllabic, tongue-twisting names: "Pteranodon, Tyrannosaurus, Brontosaurus!" "Stegosaurus, Velociraptor!" Sometimes these creatures would feature in plausible scenarios, running, jumping, and flying. But just as often, the children would move fluidly into the realm of fantasy, inventing scenarios where dinosaurs interacted with humans and animals from another time period, joining along in play or vanquishing common enemies. The transitions were matter of fact, a bit of everyday magic from children who had no need to separate reality from fiction. For instance, one story was set in a dinosaur museum before shifting the action directly to Dinosaurland.

And then we looked at the dinosaur museum.

Of dinosaur bones.

And then we went to.

Where the Hobby Kids were.

And then we said "Hi" to them.

And the Hobby Kids didn't know my name.

So I told them. My name.

And then we all see the dinosaurs moving.

Swish.

Swish.

Swish.

And we all saw big T Rex that was like going.

Roar. 
Roar.

Roar.

Roar.

Roar.

And then we saw pterodactyls.

And then we saw big dinosaurs.

And then we saw velociraptors....

Then we went to Dinosaurland.

And then I maded a friend with a pteranodon.

And I chased.

And I had a little fun with the velociraptor.

And I chaseded him.

Like that.

And then I was like, going like crazily.

When, and James was going like crazily.

When I was blowing bubbles.

And the dinosaurs too.

Like.

(Noises).

Like that.

And you too.

You were like going like.

(Noises).

Like crazy.

And then I went like, "You big thingy."

Then I was.

Then I went back home.

Emma

With the space to explore the magical and the scientific through the language of story, the children began to attend more closely to the interests and desires of the other children in the circle, increasingly telling stories that elicited laughter and approval from others. Within the context of this sustained idea of Dinosaurland and the increasingly social turn in storytelling, the children continued to combine the real and imagined, the everyday and fantastic. It was at this time that Alex, again, provided the catalyst, telling a story about dinosaurs eating dinner, with children's and teachers' body parts serving as the main course. 


\section{Imagining a new world: A catalytic moment of joyful invention}

The introduction of the idea of dinosaurs consuming classmates and teachers for a meal brought a new energy to the storytelling as children straddled the real and imagined and played with the potential violence of carnivorous creatures.

Alex: Once upon a time. I was walking in Dinosaurland.

Teacher Madison: That's a good start.

Alex: I played with dinosaurs.

And one of them said, "You can't come to my house."

Then the other one said, "You can come to my house."

And then I went to the dinosaur's house.

And it had full of stuff.

And stuff.

And even more stuff.

And even dead humans.

That they, he.

That dinosaurs ate them.

And Damon came to Dinosaurland with me.

And Nadim, and Miguel, and Damon, and Sadiq, and Aaden.

And they, and I.

And the dinosaur said, "Would you like to come to my house for dinner?"

And Miguel said.

And I said, "Miguel will do it."

And he said, "No way."

Then the dinosaur ate him up for breakfast.

Then Teacher Madison came over and said, "Don't eat Miguel up."

Then a bald came along.

Then Sadiq had no hair.

And then because the dinosaur ate him for salad.

He had bald hair.

Uh huh. And he ate it for salad.

And then Damon came along and had no nose.

Miguel: Then you cannot smell!

Alex: Then Nadim came along and he had no ears. 
Because the T Rex.

Because the dinosaur ate them for cucumbers.

And Aaden had no eyeballs.

Because the dinosaur ate them for little potatoes.

And then Miguel came back along with no mouth.

Then Damon.

Then Nadim.

Then Sadiq came along and he had no shirts.

Aaden: Why?

Alex: Yep.

Then Amal came along and then.

She had no arm.

Because the dinosaur ate them for long carrots.

(Children laughing.)

Teacher Sofia: Too loud, guys.

Alex: And then Damon came along and he had no Pikachu.

Because the dinosaur ate it for lightning.

Um and then, Teacher Sofia came along and she had no lips.

Because the dinosaur ate them for.

For a tomato.

And Sadiq came back along and he had no legs.

Because the dinosaur ate them for even more long carrots.

And Miguel came along and he had no ( ) or clothes, or mouth, or head, or arms, or feet, or shoes, or anything!

Because he ate them.

Because he was a ghost.

All done.

Reflecting back on this storytelling moment, we consider it a catalyst because it at once built upon previous stories and provided an exciting departure for the children, sending the entire group's storytelling in new directions. Stories up to this point had been met with quiet listening or a few comments. Now, fits of uproarious laughter came over the group as they described how a human meal might compare to a side dish for a dinosaur. In future iterations of the dinosaur dinner stories, children clamoured to be included, listening with intense interest and nominating themselves and others as the next tasty bite for the dinosaur. Whether it was the reality of never having to fear such a fate in their real world or the freedom to discuss a potentially taboo topic in front of the teachers and researchers, the inclusion of their friends and a teacher as snacks proved to be an irresistible combination. Nonsensical elements like a dinosaur eating the teacher's lips as a tomato were seamlessly and matter-of-factly combined 
with more abstract concepts like the dinosaur eating Pikachu for lightning or Miguel becoming disembodied, having been eaten by the dinosaur and becoming a ghost. Hilarity ensued.

In the often-overlooked world of children, fantastical elements readily combine with the everyday. Dinosaurs, given their status as something at once real and fantastic, straddle the factual/imagined in a way uniquely suited to the worlds of children's stories, in which they entangle their existing friendships, well-known places and landscapes, characters from popular culture, and the communal imagined world of Dinosaurland.

\section{Dinner at Dinosaurland: Inspiring new directions}

Alex's story transformed Dinosaurland and the story circle, with the eating of friends' body parts becoming a repeated convention. The story was such a hit that it was often imitated in subsequent story circles. In Dinosaurland, it seemed, dinner was always on. Using this winning formula, Sadiq riffed on Alex's story, including his peers one by one.

Once upon a time.

I come with no hair.

Because the dinosaur eat it.

For a potato hair.

(Laughter).

And.

Damon come.

And he do not have.

Any mouth.

Be because.

Because the dinosaur ate it.

For a Superman.

(Laughter).

And there comed Aaden.

And he.

Had.

No hands.

Because the dinosaur ate it for a water.

(Laughter).

And come Miguel and he have no arms.

And the dinosaur eat it for, uh, macaroni and cheese with pizza.

And come Damon.

And he have no nose.

Because the dinosaur eat it for Aaden. 
And come Alex and he do not have.

And he wear glasses.

I mean he do not have any ears.

And the dinosaur eat it for, for a pizza.

Sadiq

As the weeks passed, storying the devouring of each child continued, first with references to Dinosaurland and then with a detailing of the dinosaur's insatiable hunger. In the following vignette, children advance the story through a more coconstructed, dialogic process.

Sadiq: ... And come Miguel and he has no shoes.

Because the dinosaurs eat it for a apple.

And come me and I have no.

Alex: Pants?

Sadiq: No pants.

And come Nadim and he has no.

Alex: Shirt?

Sadiq: No shirt.

And come Aaden and he has no.

Miguel: Pants?

Sadiq: No hands.

Because the dinosaurs eat it for $a$.

For a crunchy munchy.

And come Miguel and he has no.

And he has glasses.

Because of the dinosaurs eat it for a.

For a crunchy unchy.

Damon: Carrots.

Sadiq: And become ( ) and he had no.

Damon: Pants.

Sadiq: No head.

Because of the dinosaurs ated it for a crunch.

Crunchy unchy....

New elements, such as the "crunchy m/unchy," went on to become part of the children's shared vocabulary, enhancing the realm of Dinosaurland. One of the remarkable aspects of witnessing this group's progress was watching offerings put forward by one child make connections with others and flow into new shared stories. By design, 
story circles center the ideas and authorship of young children, envisioning children as the support for one another's learning. Repeated engagement, shared dialogue, and collective affinities do the work of extending children's ideas, rather than teacher questioning and encouragement.

The children were motivated to elaborate, extend, and amplify ideas in their stories by the engagement and reaction of their classmates. The use of new details helped children make their stories come alive in a way that everyone involved could imagine the noises and feelings of the characters interacting in their now collective world. The children were inspired to include more and more peers until everyone was involved. The infectious joy of absurd and implausible scenarios brought the group closer together and created a shared world of stories, focused on Dinosaurland.

\section{Storytelling permeating the classroom space}

Children's adventures in Dinosaurland inspired many changes in the classroom, some initiated by teachers and some authored by children. Storytelling offered a fruitful way for teachers to keep connected to the children's thinking and evolving ideas. Storytelling began to permeate classroom life as teachers invited children to story their classroom drawings. Soon, children spent the morning breakfast sharing their storytelling plans for that day's circle. They ate their lunch while retelling, commenting on, and laughing at each other's stories told during the circle earlier in the day. Teachers found inspirations for new curricular investigations in the children's weekly story circles. For example, a study of dinosaurs evolved into a study of animals that inhabit land, air, and sea.

The children continued their stories in other forms outside the circle time, pretending to be dinosaurs and initiating animal chase games on the playground. They expanded on ideas introduced in the story circle in their play with classroom blocks, natural materials, toy dinosaurs, and animal figures. Even though story circles met only once a week, storytelling permeated the classroom's everyday routines, energized children's thinking, and deepened their connection to one another.

\section{Concluding thoughts}

Storytelling in preschool classrooms has been shown to help children build a classroom community of shared ideas (Paley, 1990). However, the power of storytelling to enable children to share and sustain ideas while building solidarity in the classroom remains underappreciated in the face of increasing academic pressures in the early years. The joyful participation in the Dinosaurland stories shows how child-led storytelling makes space for children to sustain, vary, and share ideas in ways that are collaborative and inclusive. Here, Dinosaurland stands at the intersection of reality and fantasy, a place for real friendships to be solidified around a shared love for an unknown fantastical land.

The language of story invites thinking and feeling, imagining and believing, listening, dialoguing, and connecting. Stories make up an important part of the hundred languages of children (Malaguzzi, 1998) because, through storytelling, children come to experience and cocreate the rich intertwinings of "work and play, reality and fantasy, science and imagination, sky and earth, reason and dream” (Malaguzzi, 1998, p. 3).

By dedicating space to storytelling that brings reason and dream together, story circles provide the necessary conditions for children to be in dialogue with one another and their lived everyday environments. Teachers carefully compose story circle groups, inviting children of different backgrounds and abilities who, based on classroom interactions, are likely to learn well together and from one another. Bringing the group together each week, teachers listen, facilitate turn taking, and build on children's ideas outside of the circle through classroom conversations, studies, and the introduction of classroom materials aimed at enhancing children's exploration of shared ideas. As Alex's singular moment of joyful invention shows, story circles "activate within children the desire and will and great pleasure that comes from being the authors of their own learning" (Malaguzzi, 1994, p. 3).

Ultimately, it is in their invented worlds, like Dinosaurland, where children bring about the most fantastic realization of some of their most urgent concerns, and where educators can find inspiration for ways to enrich their 
teaching repertoire and day-to-day classroom activities and routines. The teachers in this study continue to wonder: What place do ferocious storytelling turns like dinosaurs eating teachers and children have in our classrooms? How can our existing child-centered practices be enhanced by creating, facilitating, and protecting the space for children's imaginative storytelling flights, however gruesome they may be? Alex's catalyzing idea of dining dinosaurs shows how a different kind of teaching engagement, energy, and questions can be sparked when the dynamics of power are shifted to center child curiosities even when what children story is irreverent, ferocious, and lives on the boundaries of what early childhood teachers more typically invite and encourage in the classroom. What might happen if we accept the invitation for dinner at Dinosaurland?

\section{Note}

This work was supported by a grant (16-0007PCF) from the Caplan Foundation for Early Childhood to Portland State University and by the Portland State University Office of Academic Affairs. 


\section{References}

Flynn, E. E. (2016). Language-rich early childhood classroom: Simple but powerful beginnings. The Reading Teacher, 70(2), 159-166. https://doi.org/10.1002/trtr.1487

Flynn, E. E. (2020). "Rapunzel, Rapunzel, lanza tu pelo": Storytelling in a transcultural, translanguaging dialogic exchange. Reading Research Quarterly. https://doi.org/10.1002/rrq.367

Flynn, E. E., Hoy, S., Lea, J., García, M. A. (2019). Translanguaging through story: Empowering children to use their full language repertoire. Journal of Early Childhood Literacy. https://doi.org/10.1177/1468798419838569

Gandini, L., \& Morrow, L. (2016). The hundred languages in ministories. Davis.

Malaguzzi, L. (1994). Your image of the child: Where teaching begins. Child Care Information Exchange. https://www.reggioalliance.org/ downloads/malaguzzi:ccie:1994.pdf

Malaguzzi, L. (1998). No way. The hundred is there. In C. P. Edwards, L. Gandini, \& G. E. Forman (Eds.), The hundred languages of children: The Reggio Emilia approach-Advanced reflections. Greenwood.

Paley, V. G. (1990). The boy who would be a helicopter. Harvard University Press.

Wiggins, G., \& McTighe, J. (2005). Understanding by design. ASCD. 